Resolution of the reaction mixture and isolation of the triester product can be accomplished by using HPLC $(4.6 \times 250 \mathrm{~mm}$ Hypersil-ODS with $0.02 \mathrm{M} \mathrm{KH}_{2} \mathrm{PO}_{4}, \mathrm{pH} 5.5$, and a methanol gradient). Modification of the phosphorothioate was observed to be more efficient for the single-stranded d[CGCA(s)AAAAAGCG] fragment than the self-complementary eicosomer, d[CGTACTAGTT(s)AACTAGTACG]. This difference in reactivity was partially overcome when the reaction mixture was heated at $50^{\circ} \mathrm{C}$. In the absence of the phosphorothioate diester, control reactions using native oligodeoxynucleotides did not result in any significant labeling. ${ }^{12}$

The unlabeled dodecamer helix, d[CGCA(s)AAAAAGCG]·d[CGCTTTTTTGCG], exhibited a $T_{\mathrm{m}}$ of $55^{\circ} \mathrm{C}$, and this was indistinguishable from the $T_{\mathrm{m}}$ values obtained for the PROXYL-labeled ( $a$ in Figure 1) or drug-labeled ( $b$ in Figure 1) helices. The $T_{m}$ value for the self-complementary eicosomer, d[CGTACTAGTT(s)AACTAGTACG] ${ }_{2}$, with two labels was also largely unchanged $\left(68.5^{\circ} \mathrm{C}\right)$ in comparison to the unlabeled fragment $\left(T_{\mathrm{m}}=67^{\circ} \mathrm{C}\right)$.

The hydrolytic stability of the phosphorothioate triesters is an important practical consideration for the value of such derivatives in many studies. Hydrolysis of the triesters proceeded by desulfurization (monitored by HPLC and confirmed by comparison with authentic standards). We have not yet examined the fate of the reporter group in these reactions. No detectable cleavage of the oligodeoxynucleotide at the point of attachment was observed. This agrees with the results of ethylated or hydroxyethylated derivatives, which result in primarily desulfurization and only very minor amounts of chain cleavage. ${ }^{6}$

Less than $5 \%$ of the Tp(s)T triester carrying the PROXYL spin label was hydrolyzed after $24 \mathrm{~h}$ at $\mathrm{pH} 7$. At $\mathrm{pH} 8$ this increased to $28 \%$, and at $\mathrm{pH} 10$ the triester was completely hydrolyzed within $11 \mathrm{~h}$. With longer fragments, the hydrolytic stability of the triester increased [the labeled dodecamer was hydrolyzed $<1 \%, 30 \%$, and $99 \%$ at $\mathrm{pH}$ values 7,8 , and 10 , respectively; the values for the eicosomer were $<1 \%, 2 \%$, and $63 \%(24 \mathrm{~h})]$. The triester prepared from a $\gamma$-bromo- $\alpha, \beta$-unsaturated carbonyl (b in Figure 1 ) exhibited stability similar to that of the PROXYL-labeled derivatives while that resulting from reaction with the aziridinyl sulfonamide (c in Figure 1) was more stable [the $\mathrm{Tp}(\mathrm{s}) \mathrm{T}$-labeled triester was hydrolyzed $<1 \%(\mathrm{pH} 7), 5 \%(\mathrm{pH} 8)$, and $34 \%(\mathrm{pH} 10)$ after 24 $h$ at ambient temperature].

It is noteworthy that the triester produced from 1,5-I-AEDANS and $\mathrm{Tp}(\mathrm{s}) \mathrm{T}$ was significantly less stable than the PROXYL-labeled derivative although the triesters formed both resulted from iodoacetamides. ${ }^{13}$ The AEDANS-labeled dimer exhibited $19 \%(\mathrm{pH}$ 7) and $88 \%(\mathrm{pH} 8$ ) hydrolysis $(24 \mathrm{~h}$ ); it was completely hydrolyzed within $2 \mathrm{~h}$ at $\mathrm{pH} 10$. However, the AEDANS-labeled dodecamer (d in Figure 1) exhibited only $<1 \%, 49 \%$, and $99 \%$ hydrolysis at the same respective $\mathrm{pH}$ values $(24 \mathrm{~h})$.

The ability to attach reporter groups (covalently) where desired on the DNA backbone should simplify studies involving protein binding, resonance energy transfer, structural analyses and nucleic acid dynamics. By employment of the appropriate functional group, it should additionally be possible to attach a variety of derivatives including, but not limited to, peptides and proteins,

(12) At $50^{\circ} \mathrm{C}, \mathrm{HPLC}$ analysis of the dansylaziridine reaction indicated the presence of minor products, suggesting some nonspecific reaction with the DNA. Labeling conducted at $25^{\circ} \mathrm{C}$ ( $\mathrm{pH} 8.0$ ) proceeded more slowly, but we were unable to detect the presence of any species other than the desired product and starting materials. However, we cannot exclude the possibility of some nonspecific modification of the DNA even at $25^{\circ} \mathrm{C}$.

(13) An additional dodecamer was labeled with the bromoacetamido derivative $i$, Although the three acetamido-linked adducts are similar in structure, that prepared from i proved to be more stable than either a or $d$ (Figure 1) (only $13 \%$ of the triester formed from i was hydrolyzed after 24 $\mathrm{h}$ at $\mathrm{pH} 8.0$ ). This variation in stability of the acetamido-linked probes is under continuing study.

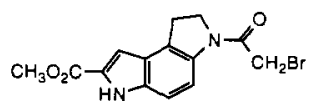

antibiotics, antineoplastics, and antivirials.

Acknowledgment. We acknowledge the technical assistance of Nicole Narekian and thank Prof. Dale Boger and Dr. S. A. Munk, Purdue University, for the preparation of the CC-1065 analogues (compound $i^{13}$ and the analogue used to prepare derivative $b$, Figure 1) and Prof. Fritz Eckstein, Max-Planck Institut, Goettingen, West Germany, for continued scientific discussions. This work was supported by a grant from the National Institutes of Health (GM 37065).

\section{Cyclopropyl Anion as an Allyl Anion Synthon. Novel Synthesis of Butadienes by Nickel-Catalyzed Coupling of Cyclopropyl Grignard Reagents with Dithioacetals ${ }^{1}$}

Dennis K. P. Ng ${ }^{2 a}$ and Tien-Yau Luh*,2b

\author{
Department of Chemistry \\ National Taiwan University \\ Taipei, Taiwan, Republic of China \\ Department of Chemistry \\ The Chinese University of Hong Kong \\ Shatin, N.T., Hong Kong \\ Received August 1, 1989
}

The synthetic utility of ring-opening reactions of cyclopropyl groups is rich. ${ }^{3}$ The rearrangement of cyclopropylcarbinyl organometallic species to homoallylic moieties has recently received much attention. ${ }^{4}$ However, the applications of these reactions in the synthesis of butadienes have been rare. ${ }^{5}$ To our knowledge, there has been no report with use of the cyclopropyl Grignard reagent as the allyl anion synthon in the synthesis of conjugated dienes. We recently uncovered several useful coupling reactions of dithioacetals with Grignard reagents in the presence of the nickel catalyst ${ }^{6}$ to afford the corresponding olefins $\mathrm{s}^{7,8}$ or geminal dimethyl products. ${ }^{8,9}$ When cyclopropylmagnesium halide is employed in this coupling reaction, the organometallic intermediate 1 is expected to rearrange ${ }^{4}$ to homoallylic organonickel species 2 , which would rapidly undergo $\beta$-elimination to give butadiene (eq 1). We

(1) Part 30 of the series Transition Metal Promoted Reactions

(2) (a) Recipient of the Croucher Foundation studentship, 1988-90. (b) To whom correspondence should be addressed at NTU.

(3) For recent reviews, see: (a) Reissig, H.-U. In The Chemistry of Cyclopropyl Group; Rappoport, Z., Ed.; Wiley: Chichester, 1987; Chapter 8. (b) Binger, P.; Büch. H. M. Top. Curr. Chem. 1987, 135, 77. (c) Salaüm, J. R. Y. Top. Curr. Chem. 1988, 144, 1. (d) Reissig, H.-U. Top. Curr. Chem. 1988, 144, 75. (e) Wong, H. N. C.; Hon, M.-Y.; Tse, C.-W.; Yip, Y.-C.; Tanko, J.; Hudlicky, T. Chem. Rev. 1989, 89, 165.

(4) (a) Bullock, R. M.; Samsel, E. G. J. Am. Chem. Soc. 1987, 109, 6542. (b) Bullock, R. M.; Rappoli, B. J.; Samsel, E. G.; Rheingold, A. L. J. Chem. Soc., Chem. Commun. 1989, 261. (c) Donaldson, W. A.; Brodt, C. A. J. Organomet. Chem. 1987, 330, C33. (d) Hill, E. A.; Park, Y.-W. J. Organomet. Chem. 1988, 356, 1. (e) Fournet, G.; Balme, G.; Gore, J. Tetrahedron Lett. 1987, 28, 4533. (f) Fournet, G.; Balme, G.; Gore, J. Tetrahedron 1988, 44, 5809. (g) Fournet, G.; Balme, G.; Barieux, J. J.; Gore, J. Tetrahedron 1988, 44, 5821. (h) Goddard, R.; Green, M.; Hughes, R. P.; Woodward, P. J. Chem. Soc. Dalton Trans. 1976, 1880 .

(5) (a) Pinke, P. A.; Stauffer, R. D.; Miller, R. G. J. Am. Chem. Soc. 1974, 96, 422. (b) Salomon, R. G.; Salomon, H. F.; Kachinske, J. L. C. J. Am. Chem. Soc. 1977, 99, 1043. (c) Doyle, M. R.; van Leusen, D. J. Org. Chem. 1982, 47, 5326. (d) Sarel, S.; Langbeheim, M. J. Chem. Soc., Chem. Commun. 1979, 73. (e) Sarel, S. Acc. Chem. Res. 1978, Ll, 204 and references therein. (f) Chiusoli, G. P.; Costa, M.; Melli, L. J. Organomet. Chem. 1988, 358,495 .

(6) (a) Okamura, H.; Miura, M.; Takei, H. Tetrahedron Lett. 1979, 20, 43. (b) Wenkert, E.; Ferreira, T. W.; Michelotti, E. L. J. Chem. Soc., Chem. Commun. 1979, 637

(7) (a) Ni, Z.-J.; Luh, T.-Y. J. Chem. Soc., Chem. Commun. 1987, 1515. (b) Ni, Z.-J.; Luh, T.-Y. J. Org. Chem. 1988, 53, 2129. (c) Ni, Z.-J.; Luh, T.-Y.J. Chem. Soc., Chem. Commun. 1988, 1011 . (d) Ni, Z.-J.; Luh, T.-Y. J. Org. Chem. 1988, 53, 5582

(8) For review see: Luh, T.-Y.; Ni, Z.-J. Synthesis, in press

(9) Yang, P.-F.; Ni, Z.-J.; Luh, T.-Y. J. Org. Chem. 1989, 54, 2261. 
Table I. Reaction of Dithioacetal with Cyclopropyl Grignard Reagent

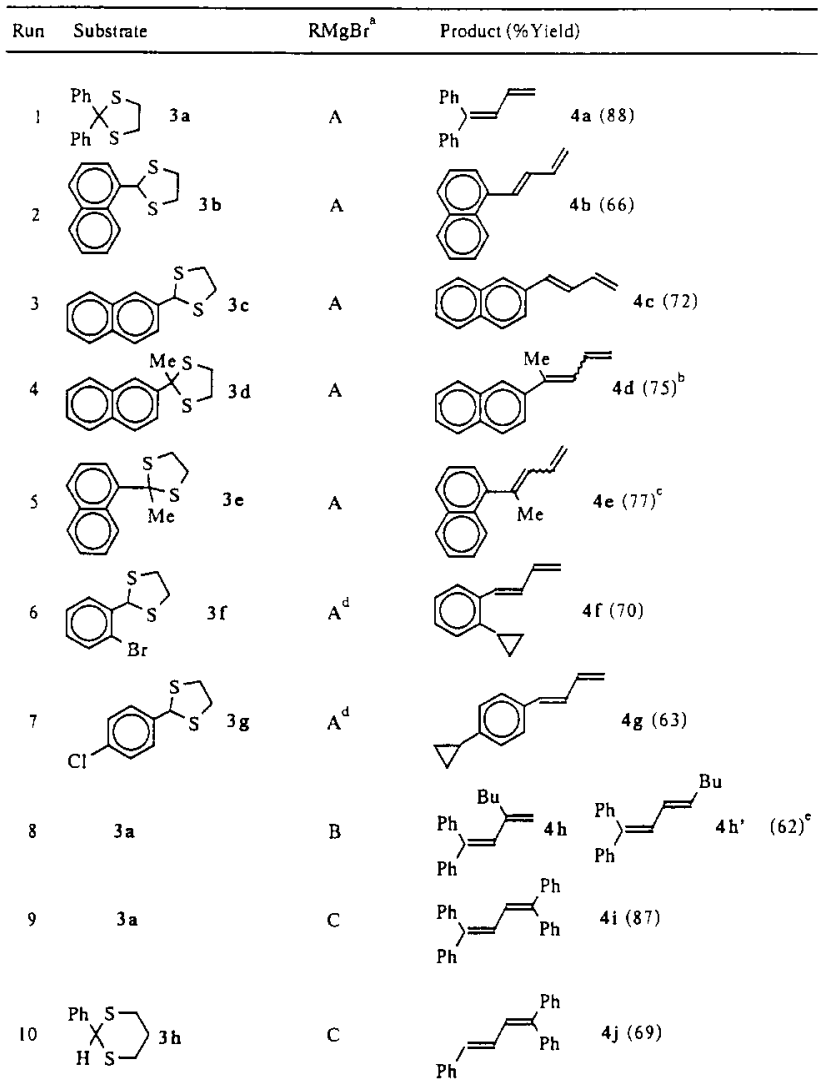

${ }^{a} 4$ equiv of $\mathrm{RMgBr}$ were used unless otherwise specified. $\mathrm{A}, \mathrm{R}=$ cyclopropyl, solvent benzene; $\mathrm{B}, \mathrm{R}=(E)$ - and $(Z)$-2-butylcyclopropyl, solvent toluene; $\mathrm{C}, 2,2$-diphenylcyclopropyl, solvent toluene. ${ }^{b} E / Z=$ 13. ${ }^{\prime} E / Z=5$. ¿ 5 equiv of $\mathrm{RMgBr}$ were employed. ' $4 \mathrm{~h} / 4 \mathrm{~h} '=1$.

describe here the unprecedented usage of such rearrangement in the synthesis of butadienes.

$$
\supset_{[\mathrm{Ni}]} \longrightarrow[\stackrel{[\mathrm{Ni}]}{\rightleftharpoons} \cdot \overrightarrow{\cdot[\mathrm{Ni}]-\mathrm{H}}
$$

In a typical procedure, dithioacetal was treated under nitrogen atmosphere overnight with 4 equiv of cyclopropylmagnesium bromide in the presence of $5 \mathrm{~mol} \%$ of $\mathrm{NiCl}_{2}\left(\mathrm{PPh}_{3}\right)_{2}$ in refluxing benzene or toluene. After the usual workup and chromatographic separation, the corresponding dienes were obtained in satisfactory yields. The results are summarized in Table $\mathrm{I} .{ }^{10}$ Benzophenone dithioacetal (3a) gave 1,1-diphenylbutadiene (4a) in $88 \%$ yield (entry 1). Various dithioacetals of aromatic aldehydes reacted smoothly (entries 2 and 3 ). The reactions with 2-aryl-2methyldithiolanes behaved similarly to afford the corresponding dienes (entries 4 and 5). The stereochemistries of the $C_{1}-C_{2}$ double bond in these products, whenever applicable, are predominantly, if not exclusively, in the $E$ configuration. These assignments were based on the ${ }^{1} \mathrm{H}$ NMR results (coupling constants and/or 2-D NOESY experiments). The observed selectivity is consistent with the requirement of cis coplanarity of the carbon-nickel bond and the $\beta, \gamma$ bond in the cyclopropyl moiety, and the conformer $5 \mathbf{a}$ would be more stable than the conformer $\mathbf{5 b}$.

It is well-documented that aryl halide can couple with Grignard reagents under the reaction conditions. ${ }^{11}$ Consequently, substrates containing such functionality would also react, hence both cy-

(10) All new compounds gave satisfactory spectroscopic properties $\left({ }^{1} \mathrm{H}\right.$ and ${ }^{13} \mathrm{C}$ NMR, IR, and MS) and accurate mass measurements. The physical data of dienes and related compounds are summarized in the supplementary material.

(11) Kumada, M. Pure. Appl. Chem. 1980, 52, 669.

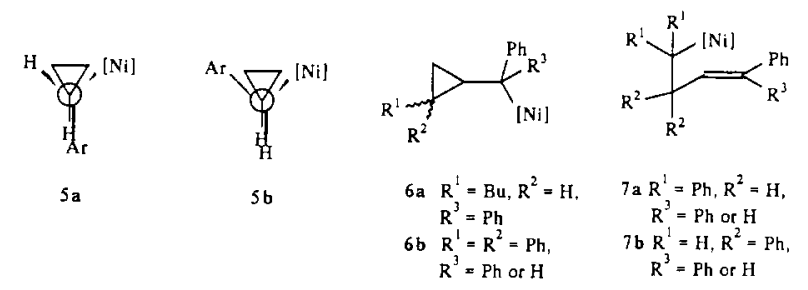

clopropyl and butadienyl moieties being introduced in one step (entries 6 and 7).

Cyclopropyl Grignard reagents having a substituent at the $\mathrm{C}_{2}$ position expectedly gave a mixture of two regioisomers (entry 8 ). Intermediate 6a may undergo a nonselective ring-opening process followed by a rapid $\beta$-hydride elimination to give the respective products. When both hydrogens at the $\mathrm{C}_{2}$ position were replaced by substituents, dienes having substituents at both terminal carbons were obtained as the sole products (entries 9 and 10). Intermediate 6b may rearrange to $7 \mathbf{a}$ and $7 \mathbf{b}$. Although $7 \mathbf{b}$ may be less crowded or more stable than $\mathbf{7 a}$, it cannot undergo a further elimination reaction. Alternatively, $7 \mathbf{a}$ may proceed $\beta$-elimination to give diene.

The reactions with bicyclic Grignard reagent are interesting. A mixture of isomeric non-conjugated dienes $\mathbf{8}$ and 9 was obtained (eq 2). As mentioned before, cis coplanarity between the car-

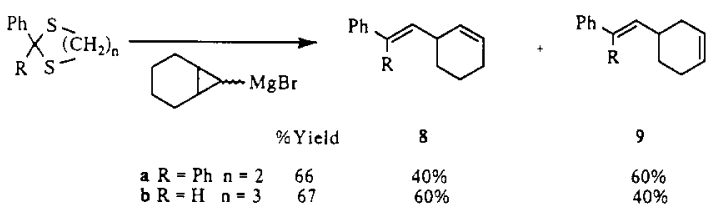

bon-nickel bond and the carbon-carbon bond to be migrated is required for the ring-opening process, resulting in the formation of intermediate $10 . \beta$-Hydride elimination of $\mathbf{1 0}$ will give 8 . Isomer 9 was obtained from the isomerization of 8 by the addition and elimination of nickel hydride species generated in situ. The stereochemical requirement prohibits the migration of the double bond to conjugated diene.

The reaction of tetralone dithioacetal (11) gave in $66 \%$ yield a mixture of vinyl cyclopropane (12) and butadiene (13) in a 2 to 1 ratio. Presumably, the cyclopropylcarbinyl intermediate here is highly crowded, hence the ring-opening process and simple $\beta$-hydride elimination step becoming nonselective.

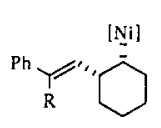

10

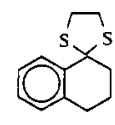

11<smiles>C=C1C=CCc2ccccc21</smiles>

12

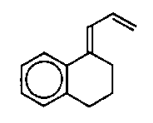

13
Throughout this investigation, we have never observed any cyclopropylidene derivatives. However, cyclobutylidene products 14 were obtained as the sole products when cyclobutyl Grignard reagent was allowed to react with dithioacetals under similar conditions (eq 3). Apparently, the participation of the carbon-<smiles>[R18]C(C)CCC1CCSC1([R])[R]</smiles><smiles>[R]C([R])=C1CCC1</smiles(3)

14a $R^{\prime}=R^{2}=\mathrm{Ph} \quad 70 \%$

$$
\text { b } R^{1}=2 \cdot \text { Naph, } R^{2}=\text { H } \quad 72 \%
$$

carbon bond in the migration process is less favorable with four-membered-ring substrates than with three-membered-ring counterparts

In summary, we have demonstrated an unprecedented procedure using cyclopropyl anion as allyl anion synthon for the convenient synthesis of butadienes. ${ }^{12}$ The reaction is simple and starting materials are easily accessible. The application of this reaction in synthesis is in progress.

(12) The use of allyl instead of cyclopropyl Grignard reagents gave a mixture of products including geminal diallylated compounds. Mei, N.-W. Luh, T.-Y. Unpublished results. 
Acknowledgment. We thank the National Science Council of Republic of China and the Croucher Foundation of Hong Kong for support. D.K.P.N. thanks the Croucher Foundation for a studentship.

Registry No. 3a, 6317-10-8; 3b, 86201-62-9; 3c, 77853-39-5; 3d 85102-56-3; 3e, 85102-58-5; 3f, 113509-22-1; 3g, 23229-32-5; 3h, 5425-44-5; 4a, 4165-81-5; 4b, 101300-69-0; 4c, 123751-89-3; (E)-4d, 123751-90-6; (Z)-4d, 123751-96-2; (E)-4e, 123751-91-7; (Z)-4e 123751-97-3; 4f, 123751-92-8; 4g, 123751-93-9; 4h, 123751-94-0; 4h', 123751-95-1; 4i, 1450-63-1; 4j, 20235-61-4; 8a, 123751-98-4; 8b, $119946-57-5 ; 9 a, 123751-99-5 ; 9 b, 100763-29-9 ; 11,42196-84-9 ; 12$, 123752-00-1; 13, 123752-01-2; 14a, 1432-53-7; 14b, 123752-02-3; $\mathrm{NiCl}_{2}\left(\mathrm{PPh}_{3}\right)_{2}, 14264-16-5$; cyclopropylmagnesium bromide, 23719-80-4; (E)-2-butylcyclopropylmagnesium bromide, 123752-03-4; (Z)-2-butylcyclopropylmagnesium bromide, 123752-04-5; 2,2-diphenylcyclopropylmagnesium bromide, 123752-05-6; bicyclo[4.1.0] heptan-7-ylmagnesium bromide, 123752-06-7; cyclobutylmagnesium bromide, 13384-48-0.

Supplementary Material Available: Physical data (IR, NMR, $\mathrm{mp}$ ) of dienes and related compounds (3 pages). Ordering information is given on any current masthead page.

\section{A Novel Tetranuclear Manganese Complex That Displays Multiple High-Potential Redox Processes. Synthesis, Structure, and Properties of $\left\{\left[\mathrm{Mn}_{2}(\mathrm{TPHPN})\left(\mathrm{O}_{2} \mathrm{CCH}_{3}\right)\left(\mathrm{H}_{2} \mathrm{O}\right)\right]_{2} \mathrm{O}\right\}\left(\mathrm{ClO}_{4}\right)_{4} \cdot 2 \mathrm{CH}_{3} \mathrm{OH}^{1}$}

Michael K. Chan and William H. Armstrong*

Department of Chemistry, University of California Berkeley, California 94720

Received June 30, 1989

As the primary source of atmospheric dioxygen, photosynthetic water oxidation is an essential process for aerobic organisms. This four-electron, four-proton reaction occurs at the photosystem II oxygen-evolving complex (PSII OEC) in green plants and algae. While it is known that four manganese atoms per PSII OEC are required for optimal oxygen evolution activity, there is no consensus as to the precise arrangement of the $\mathrm{Mn}$ atoms, nor is the mechanism of water oxidation well understood, ${ }^{2}$ One prevalent notion is that the manganese center functions to store four oxidizing equivalents at an electrochemical potential high enough $(\geq 0.8 \mathrm{~V}$ vs $\mathrm{NHE}$ at $\mathrm{pH}=7$ ) to carry out the oxidation of water to dioxygen. ${ }^{3}$ It is thought that two water molecules (or deprotonated derivatives thereof) may be transformed to dioxygen by a concerted single oxidative process. In the Kok S-state scheme for the PSII OEC catalytic cycle, ${ }^{4}$ this four-electron process would occur between the $\mathrm{S}_{4}$ and $\mathrm{S}_{0}$ states. Within this conceptual framework, it is clear that one criterion for a functional synthetic analogue is that it should exhibit four high-potential redox processes. Several high-valent tetranuclear species have been reported; ${ }^{5-8}$ however, judging by conclusions from recent XAS

(1) Abbreviations used: HTPHPN, $N, N, N^{\prime}, N^{\prime}$-tetrakis(2-pyridylmethyl)-2-hydroxypropane-1,3-diamine; PSII OEC, photosystem II oxygenevolving complex; XAS, X-ray absorption spectroscopy; SSCE, saturated sodium calomel electrode; $\mathrm{HBpz}_{3}$, hydrotris(1-pyrazolyl) borate; tacn, 1,4,7triazacyclononane; bpy, 2,2'-bipyridine; L-Im, 2,6-bis[[[bis(1-methy]imidazol-2-yl)methyl]amino]methyl]-4-methylphenol; Him, imidazole.

(2) (a) Dismukes, G. C. Photochem. Photobiol. 1986, 43, 99. (b) Amesz, J. Biochem. Biophys. Acta 1983, 726, 1. (c) Brudvig, G. W. J. Bioenerg. Biomembr. 1987, 19, 91. (d) Babcock, G. T. In New Comprehensive Biochemistry: Photosynthesis; Amesz, J., Ed.; Elsevier: Amsterdam, 1987; pp 125-1 58. (e) George, G. N.; Prince, R. C.; Cramer, S. P. Science 1989, 243, 789-791.

(3) See, for example: Luneva, N. P.; Knerelman, E. I.; Shafirovich, V. Ya.; Shilov, A. E. New J. Chem. 1989, 13, 107-110.

(4) Kok, B.; Forbush, B.; McGloin, M. Photochem. Photobiol. 1970, 11, 457.

$0002-7863 / 89 / 1511-9121 \$ 01.50 / 0$

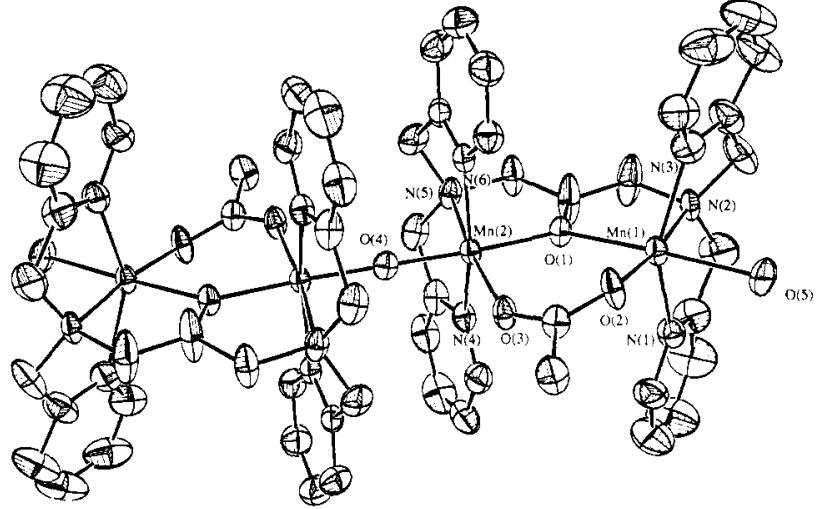

Figure 1. Structure of $\left\{\left[\mathrm{Mn}_{2}(\mathrm{TPHPN})\left(\mathrm{O}_{2} \mathrm{CCH}_{3}\right)\left(\mathrm{H}_{2} \mathrm{O}\right)\right]_{2} \mathrm{O}\right\}^{4+}$ (1) showing the $40 \%$ probability thermal ellipsoids and atom labeling scheme. Hydrogen atoms are omitted for clarity. Unlabeled atoms are related to labeled ones by an inversion center. Selected interatomic distances $(\AA)$ and angles (deg) are as follows: $\mathrm{Mn}(1)-\mathrm{O}(1), 2.148(3) ; \mathrm{Mn}(1)-\mathrm{O}(2)$, 2.097 (3); $\mathrm{Mn}(1)-\mathrm{O}(5), 2.174(3) ; \mathrm{Mn}(1)-\mathrm{N}(1), 2.248$ (5); $\mathrm{Mn}(1)-\mathrm{N}(2)$, 2.281 (4); $\mathrm{Mn}(1)-\mathrm{N}(3), 2.246$ (5); $\mathrm{Mn}(2)-\mathrm{O}(1), 1.921$ (3); $\mathrm{Mn}(2)-\mathrm{O}(4)$, $1.766(1) ; \mathrm{Mn}(2)-\mathrm{O}(3), 2.096(3) ; \mathrm{Mn}(2)-\mathrm{N}(4), 2.097$ (4); $\mathrm{Mn}(2)-\mathrm{N}(5)$, 2.238 (4); $\mathrm{Mn}(2)-\mathrm{N}(6), 2.092$ (4); $\mathrm{Mn}(1) \cdots \mathrm{Mn}(2), 3.689$ (1); $\mathrm{Mn}(2) . \cdot$ $\cdot \mathrm{Mn}\left(2^{\prime}\right), 3.532(1) ; \mathrm{Mn}(2)-\mathrm{O}(4)-\mathrm{Mn}\left(2^{\prime}\right), 180.0 ; \mathrm{Mn}(1)-\mathrm{O}(1)-\mathrm{Mn}(2)$, 130.0 (2); $\mathrm{O}(1)-\mathrm{Mn}(1)-\mathrm{O}(5), 173.7$ (1); $\mathrm{O}(1)-\mathrm{Mn}(2)-\mathrm{O}(4), 175.5$ (1).

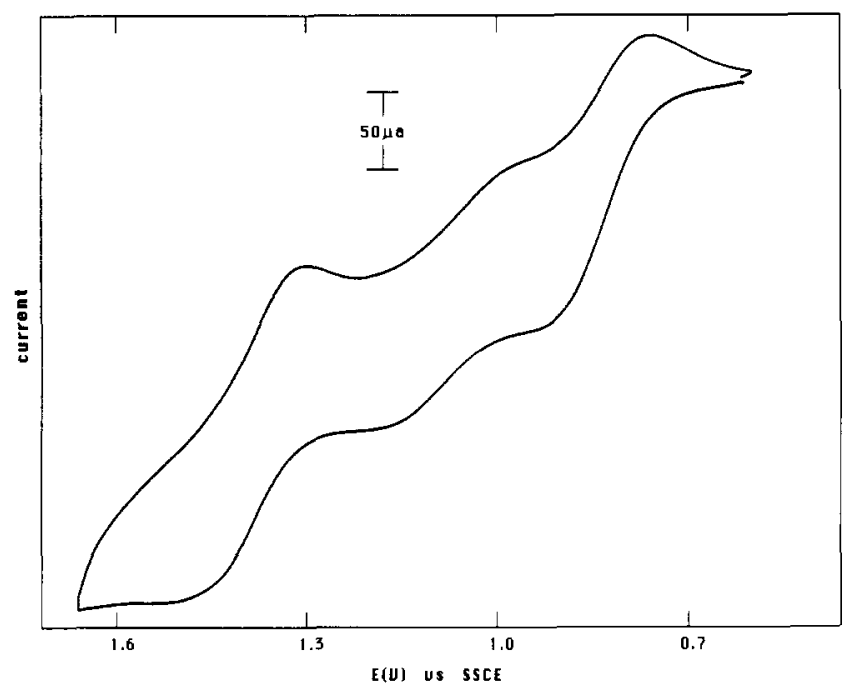

Figure 2. Cyclic voltammogram of 1 in $\mathrm{CH}_{3} \mathrm{CN}$ using $0.1 \mathrm{M} \mathrm{Et}_{4} \mathrm{NClO}_{4}$ as supporting electrolyte, a Pt working electrode, a Pt wire counter electrode, an SSCE reference electrode, and a scan speed of $50 \mathrm{mV} / \mathrm{s}$.

measurements on oriented samples of PSII OEC, ${ }^{2 e}$ none of these model complexes are structurally congruent with the native manganese aggregate, nor has it been reported that any of them, or any other polynuclear manganese complexes for that matter, exhibit multiple redox processes at high potential. In this report we describe the synthesis and structure of a novel mixed-valence $\left[\mathrm{Mn}^{\mathrm{II}}{ }_{2} \mathrm{Mn}^{\mathrm{III}}{ }_{2}\right]$ tetranuclear complex, $\left\{\left[\mathrm{Mn}_{2}(\mathrm{TPHPN})\left(\mathrm{O}_{2} \mathrm{CC}-\right.\right.\right.$ $\left.\left.\left.\mathrm{H}_{3}\right)\left(\mathrm{H}_{2} \mathrm{O}\right)\right]_{2} \mathrm{O}\right\}\left(\mathrm{ClO}_{4}\right)_{4}(\mathbf{1})$, which does indeed display several quasireversible oxidations between 0.8 and $1.4 \mathrm{~V}$ vs SSCE. Furthermore, complex 1 is the first high-valent tetranuclear species

(5) Kulawiec, R. J.; Crabtree, R. H.; Brudvig, G. W.; Schulte, G. K. Inorg. Chem. 1988, 27, 1309-1311.

(6) Wieghardt, K.; Bossek, U.; Nuber, B.; Weiss, J.; Bonvoisin, J.; Corbella, M.; Vitols, S. E.; Girerd, J. J. J. Am. Chem. Soc. 1988, 110, 7398-7411.

(7) (a) Vincent, J. B.; Christmas, C.; Huffman, J. C.; Christou, G.; Chang, H.-R.; Hendrickson, D. N. J. Chem. Soc., Chem. Commun. 1987, 236. (b) Christmas, C.; Vincent, J. B.; Huffman, J. C.; Christou, G.; Chang, H.-R.; Hendrickson, D. N. J. Chem. Soc., Chem. Commun. 1987, 1303. (c) Vincent, J. B.; Christmas, C.; Chang, H.-C.; Li, Q.; Boyd, P. D. W.; Huffman, J. C.; Hendrickson, D. N.; Christou, G. J. Am. Chem. Soc. 1989, 111, 2086-2097.

(8) Bashkin, J. S.; Chang, H.-R.; Streib, W. E.; Huffman, J. C.; Hendrickson, D. N.; Christou, G. J. Am. Chem. Soc. 1987, 109, 6502-6504. 